\title{
Voltaire, Saggio sulla poesia epica, traduzione e cura di P. Gallo
}

\section{Vittorio Fortunati}

\section{(2) OpenEdition}

\section{Journals}

\section{Edizione digitale}

URL: http://journals.openedition.org/studifrancesi/463

DOI: 10.4000/studifrancesi.463

ISSN: 2421-5856

\section{Editore}

Rosenberg \& Sellier

\section{Edizione cartacea}

Data di pubblicazione: 1 aprile 2015

Paginazione: 151

ISSN: 0039-2944

\section{Notizia bibliografica digitale}

Vittorio Fortunati, « Voltaire, Saggio sulla poesia epica, traduzione e cura di P. Gallo », Studi Francesi

[Online], 175 (LIX | I) | 2015, online dal 01 avril 2015, consultato il 18 septembre 2020. URL : http:// journals.openedition.org/studifrancesi/463 ; DOI : https://doi.org/10.4000/studifrancesi.463

Questo documento è stato generato automaticamente il 18 settembre 2020.

\section{(c) (i) (9)}

Studi Francesi è distribuita con Licenza Creative Commons Attribuzione - Non commerciale - Non opere derivate 4.0 Internazionale. 


\title{
Voltaire, Saggio sulla poesia epica, traduzione e cura di P. Gallo
}

\author{
Vittorio Fortunati
}

\section{NOTIZIA}

VOLTAIRE, Saggio sulla poesia epica, traduzione e cura di P. GALLo, prefazione di J.-M.

ROULIN, Roma, Aracne, 2014, pp. 225.

1 Pubblicato per la prima volta in lingua inglese nel 1727 (un anno prima della Henriade), tradotto e rimaneggiato dallo stesso autore nel 1733, l'Essai sur la poésie épique si distingue sotto diversi aspetti dalle numerose opere analoghe che lo hanno preceduto. Come sottolinea molto bene Jean-Marie Roulin nella sua densa prefazione (pp. 9-28), Voltaire respinge ogni pretesa normativa fondata deduttivamente sui modelli dell'antichità classica, optando per un approccio descrittivo e, modernamente, comparatistico. In altri termini, l'Essai non è un'arte poetica, ma una sorta di storia sintetica dell'epopea occidentale che, partendo da Omero, giunge fino a Milton attraverso alcune tappe rappresentate da poeti latini (Virgilio e Lucano), italiani (Trissino e Tasso), iberici (Camõens e Alonso de Ercilla). Ogni autore viene inserito nel contesto storico e culturale in cui visse e operò; in certi casi non sono trascurate le condizioni materiali della sua esistenza, con una sottolineatura (quasi «romantica», se così si può dire) dell'indigenza e dell'emarginazione di alcuni grandi poeti. Il dato più interessante, però, è che il giudizio sulle opere si ispira a una sorta di relativismo estetico: di ognuno dei poemi presi in considerazione (non esclusi quelli di Omero e Virgilio) sono messi in luce pregi e difetti, senza che a nessuno di essi venga attribuito il titolo di modello insuperabile. Ogni epopea è, per Voltaire, un prodotto caratteristico della sua epoca, anche se permane l'idea (ereditata dai Modernes del XVII secolo) di un progresso nella creazione letteraria: se l'Iliade è inimitabile, la Gerusalemme liberata le è, da molti punti di vista, superiore. 
2 Tra le opere prese in considerazione da Voltaire non compaiono, se non citati brevemente e in modo critico, i poemi epici composti in Francia: né le chansons de geste (sulle quale pesava ancora il pregiudizio, condiviso dal philosophe, verso il «barbaro» medioevo), né i poemi secenteschi ascrivibili al genere del merveilleux chrétien (quelli, per esempio, di Desmarets de Saint-Sorlin, di Scudéry, di Chapelain). Voltaire affronta, nel capitolo dedicato al Paradise Lost di Milton, l'annosa questione della mancanza di un'epopea nazionale francese e ne individua le cause principali nell'eccessiva razionalità e nella scarsa immaginazione dei suoi compatrioti (almeno in confronto ad altre nazioni europee). Nello stesso tempo, però, vengono rivendicati come valori di una possibile epica moderna la verosimiglianza e la storicità della Henriade: Voltaire, in definitiva, è convinto di riuscire laddove altri autori prima di lui hanno fallito.

3 Nell'accurata traduzione di Pierino GALLo è stata conservata, in gran parte, la punteggiatura dell'originale francese. Il testo è seguito da numerose note esplicative (pp. 189-213) e da una bibliografia (pp. 215-225), suddivisa in alcune sezioni: edizioni e traduzioni dell'Essai, opere teoriche sul genere epico, saggi critici su Voltaire e sull' Essai. 